\title{
Smart Grid Implementations for Achieving Increased Renewable Energy Proliferation in Small Island Developing States (SIDS)
}

\author{
Jonathan Kelly, Gillian Lacey ${ }^{1}$, Anju Mekkayil, Kiran Chandrakumar Jyothi, Gobind Pillai ${ }^{2}$ \\ School of Science, Engineering and Design \\ Teesside University \\ Middlesbrough, UK \\ 17.Lacey@tees.ac.uk, ${ }^{2}$ G.G.Pillai@tees.ac.uk
}

\begin{abstract}
The replacement of fossil fuel energy systems with renewable energy technologies is necessary to meet low carbon targets. However the inclusion of variable renewable energy generators in island grids can result in generation exceeding demand in instances of high renewable resource availability. A case study of Fair Isle is considered in this paper where until October 2018 the excess wind power was discarded through dump loads. The paper investigates the impacts of using electric vehicles (EVs) in the place of the dump loads to make better use of the excess power. HOMER was used to model the existing and the proposed systems and obtain power supply values. Power flow analyses on the proposed system were conducted using IPSA. The results indicate that up to $8 \mathrm{EVs}$ can be subjected to scheduled charging at a time, between 23:00 and 07:00 when there is the highest wind penetration and lowest consumer power demand.
\end{abstract}

Keywords--Demand-side management, energy storage, power quality, power system economics, power system protection

\section{INTRODUCTION}

During the Conference of Parties 21 (COP21) held in 2015 , over 190 countries signed on to a legally binding climate change agreement, which aims to prevent the increase of global atmospheric temperatures by more than $2^{0} \mathrm{C}$. The increased utilization of renewable energy technologies instead of incumbent fossil fuel energy systems was identified as a key for achieving the COP21 goals.

Several small island developing states (SIDS) including Caribbean and Pacific island nations are amongst those who have adopted the COP21 mandate and have been seeking to increase distributed renewable energy (DRE) generation on island grids, which are conventionally powered by diesel generators. In seeking to implement this, the structure, capability and interoperability of the DRE systems with the existing grid can be overlooked as primary focus is placed on renewable energy project implementation. The existing designs and operational dynamics of island grids are often unable to sustain increased penetration of stochastic renewables such as wind and solar without significantly compromising grid power quality.

Island hybrid power systems comprise of a mix of conventional and distributed renewable generators rather than the centralised generation conventionally associated with fossil fuel generators. Hybrid power systems can provide more flexible operations for modern electrical grids and offer several social, environmental and economic benefits [1]. Not only reduced $\mathrm{CO}_{2}$ emissions, but also economic benefits arise from the stoppage of transporting and bunkering of fossil fuels. It is estimated that currently $90 \%$ of the Caribbean's energy demand is met by imported fossil fuels accounting for approximately 30\% of GDP spending. This is typical of these islands and other SIDS [2].

In order to minimise the use of fossil fuels, the DRE needs to be sized larger, which means there is more likely to be an excess of generation, especially at night. This excess is historically sent to dump loads such as water heating.

The feasibility of utilising EVs instead of dump loads to make better use of excess power generation from wind power is studied in this paper using the case study of a remote inhabited island in the UK.

\section{IMPACTS OF WIND GENERATION ON POWER NETWORKS}

The advantages of using wind as the main power source on an island is clear, but aside from the problem of excess generation, there are several other drawbacks to be overcome.

\section{A. Detrimental Impact of Wind}

Fluctuations in wind power output can impact system wide balancing operations and cause localised voltage problems including instantaneous voltage drops, static voltage fluctuations and voltage flicker [3]. In small island systems weather conditions affect the entire system over a wide area and hence the impact of wind farm output fluctuations is more noticeable.

As intermittent wind power penetration increases in power systems, the balancing costs increase due to the cost of operating higher reserve capacity and providing flexibility to balance wind variability. Such costs are estimated to be in the region of $0.5-6 £ / \mathrm{MWh}$ with cost increasing proportionately with level of penetration [4]

Intermittent wind power can reduce the efficiency of conventional thermal power plants operating in tandem as such plants which were designed to operate at constant power output, will be required to frequently ramp up and down and start and stop resulting in suboptimal operations and increased fuel consumption and $\mathrm{CO}_{2}$ emissions [4].

\section{B. Methods To Mitigate The Negative Impacts}

Apart from optimum spatial distribution and high accuracy forecasting, the intermittency conundrum can be mitigated by various methods, at both generation and demand sides. 
Flexible rapid responding power plants are ideally suited to complement wind power. Such often utilise gas turbines or diesel generators for smaller systems. Solar energy can also be complementary to wind power intermittency albeit through optimized spatio-temporal allocation.

The synchronisation of wind power output and load demands by deploying demand-side management (DSM) and demand-side response (DSR) techniques, can be effective reducing the negative impacts of wind power intermittency on power systems [4].

PEVs are projected to become major demand side components of future power systems and can mitigate the negative impacts of intermittent wind power through controlled incentivised charging or discharging into the grid [4]. Very short ramp times, and agility of power changes mean that battery storage is a useful addition when optimizing DRE. The reduction of wind power intermittency impacts through a decentralized PEV charging control scheme, wherein real time virtual price market signals and existing level of charge are used as determinants in autonomously controlling the charging or discharging actions of individual PEVs [5].

Energy storage systems (ESS) can provide voltage and frequency regulation and mitigate impacts of wind power intermittency by storing excess wind power during off peak periods and releasing to the grid during periods of peak load [4]. Output smoothing, along with power system oscillation damping, reserve application, time-shifting and load demand management are some of the effects ESSs can have on power system operation in mitigating wind power intermittency [6].

The concept of vehicle -to-grid (V2G) is based on the utilization of electricity stored in electric drive vehicles to provide power to the electric grid as needed. Advancements in smart grid technologies will allow EVs to provide grid support by discharging/charging to and from the grid when needed to provide voltage and frequency support.

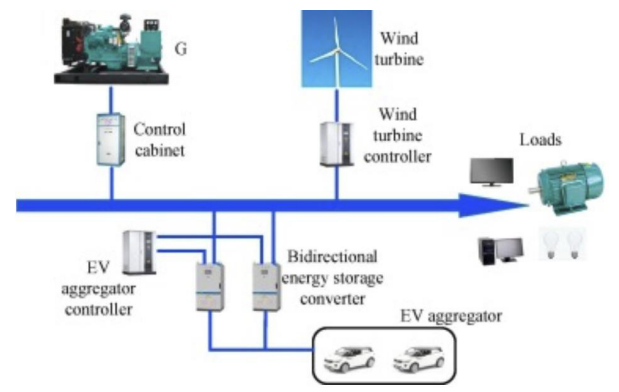

Figure 1. A standalone microgrid containing RET and EVs [5]

\section{CASE STUDY}

Fair Isle is a 2.97 sq. miles remote inhabited island in the United Kingdom located 24 miles from the main island in Shetland of which it is an administrative subject. This island, having a permanent population of approximately 80 persons living in 30 dwellings, was chosen for modelling and investigating an islanded hybrid power system used until October 2018 [10] to provide power to the island. The descriptions and Figures for the study are taken from this hybrid system.

It has a fully autonomous wind-diesel hybrid power system, with approximately $94 \%$ of the annual energy demanded being generated by wind turbines. However, $25 \%$ of the annual total wind energy converted into electricity is wasted to resistive 'dump' loads in order to maintain grid stability.

\section{A. Existing Power system}

Figure 2 presents the Fair Isle power system topology. As shown the system is configured as a 5-bus distribution network with three generation buses and two load busses linked by an underground distribution network.

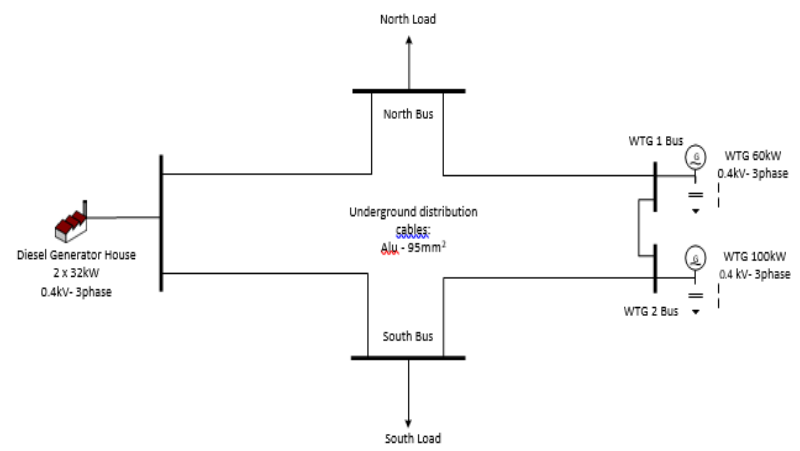

Figure 2. Topology of existing Fair Isle power system

\section{B. Load Profile}

Historical hourly domestic load profile data for Fair Isle was not available in the public domain at the time of this investigation, hence a synthetic load profile was created based on UK seasonal rural domestic load profile data and scaled to estimated peak for 30 domestic dwellings representative of the island's average load.

\section{Wind resource profile}

Monthly average meteorology statistics for Fair Isle were obtained from the UK meteorological office website as shown in Table I. The average monthly wind speeds indicate that throughout the year, the wind resource is suitable for energy generation, with July being the lowest month. It can also be seen that the winter months during which highest energy demand occurs have the best wind resource availability.

TABLE I. FAir Isle Climate Stats (Met OfFice, 2018)

\begin{tabular}{|c|c|c|c|c|c|c|}
\hline Month & $\begin{array}{c}\text { Max. } \\
\text { Temp } \\
\left({ }^{\circ} \mathbf{C}\right)\end{array}$ & $\begin{array}{c}\text { Min. } \\
\text { Temp } \\
\left({ }^{\circ} \mathbf{C}\right)\end{array}$ & $\begin{array}{c}\text { Days } \\
\text { of } \\
\text { air } \\
\text { frost }\end{array}$ & $\begin{array}{c}\text { Sunshine } \\
\text { hours }\end{array}$ & $\begin{array}{c}\text { Rainfall } \\
(\mathbf{m m})\end{array}$ & $\begin{array}{c}\text { Mean } \\
\text { monthly } \\
\text { wind } \\
\text { speed at } \\
\mathbf{1 0 m}(\mathbf{m} / \mathbf{s})\end{array}$ \\
\hline Jan & 6.7 & 3.1 & 3 & 29.4 & 101.9 & 9.8 \\
\hline Feb & 6.1 & 2.6 & 4.1 & 60.5 & 81.7 & 9.6 \\
\hline Mar & 6.7 & 3 & 3.3 & 105.9 & 85.6 & 8.9 \\
\hline Apr & 7.9 & 4.2 & 1.5 & 149.7 & 51 & 7.4 \\
\hline May & 9.9 & 6 & 0.1 & 210.6 & 41.7 & 6.5 \\
\hline Jun & 11.9 & 8.1 & 0 & 173.3 & 45.9 & 5.9 \\
\hline Jul & 13.7 & 10.1 & 0 & 144.7 & 54.9 & 5.5 \\
\hline Aug & 14.9 & 10.6 & 0 & 151.1 & 70.3 & 5.8 \\
\hline Sep & 12.8 & 9.4 & 0 & 115.6 & 83.6 & 7.2 \\
\hline Oct & 10.7 & 7.5 & 0 & 76.9 & 116 & 8.6 \\
\hline Nov & 8.7 & 5.2 & 1.2 & 38 & 113.5 & 9.1 \\
\hline Dec & 7.2 & 3.6 & 3.3 & 20.6 & 10.6 & 9.4 \\
\hline
\end{tabular}

\section{Wind Turbine}

Two fixed pitch stall regulated wind turbines are used for wind power generation on Fair Isle. Their technical descriptions are as shown in Table II [7]. The turbines are installed approximately $1 \mathrm{~km}$ apart. 
TABLE II. WIND TURBINE DETAILS

\begin{tabular}{|l|c|c|}
\hline Wind turbine & $\mathbf{6 0 k W}$ & $\mathbf{1 0 0 k W}$ \\
\hline Diameter & $15.9 \mathrm{~m}$ & $19.1 \mathrm{~m}$ \\
\hline Blades- LM x 3 & $8 \mathrm{HMT}$ & $9.7 \mathrm{HMTB}$ \\
\hline Tip pitch - deg. & 3.25 & 3.25 \\
\hline Speed - r.p.m. & 44 & 41 \\
\hline Gearbox - Fenner & L20 & M20 \\
\hline Drive ratio O.A. & $1: 32.73$ & $1: 36.35$ \\
\hline Generator & B464B & UCI274F \\
\hline Rating - kW & 96 & 132 \\
\hline KVA & 120 & 165 \\
\hline Yaw drive & Fantail & Fantail \\
\hline
\end{tabular}

\section{E. Wind power control with dump load}

Resistive dump loads attached to each turbine can accept up to $150 \%$ of the turbine rated output. During periods of excess wind, to maintain wind power stability to the grid, the dump loads resistances can be adjusted by a dump load controller (DLC) at a rate of 150 times per second to keep the system voltages and frequencies within limits [8]. In the case of Fair Isle, on average $182 \mathrm{MWh}$ of wind energy is dumped annually.

\section{F. Diesel generators}

No detailed technical description of the Fair Isle diesel generators is in the public domain. However, it is stated that there are two $32 \mathrm{~kW}$ three phase $415 \mathrm{~V}$ diesel generators presently in operation. It is assumed that these generators have similar operational characteristics to those of the Cummins range.

\section{G. Distribution network}

The island power is distributed via an underground $415 \mathrm{~V}$ three phase distribution network utilizing $95 \mathrm{~mm}^{2}$ aluminum cables [9].

\section{SIMULATION OF A TYPICAL ISLAND GRID USING POWER SYSTEM MODELLING SOFTWARE}

\section{A. HOMER model creation}

The first stage of the investigation was to create a base model in HOMER to observe the system energy performance. Key inputs into HOMER and assumptions were as follows:

1)Load profile: Figure 3 shows the synthesized island daily load profile. The variability between week days and weekends, as well as seasonal variations was modelled using 8 different profiles.

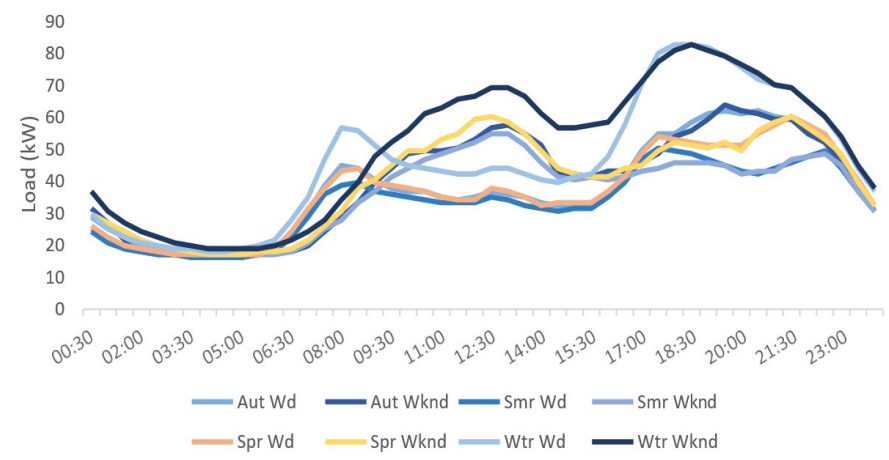

Figure 3. Synthesised Fair-Isle seasonal daily load profile

2) Wind resource profile: The wind resource is found from NOAA and illustrated in Figures 4 and 5.

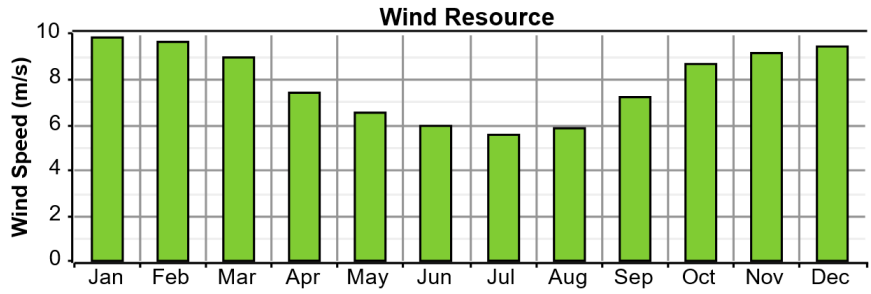

Figure 4. Fair Isle monthly average wind speeds

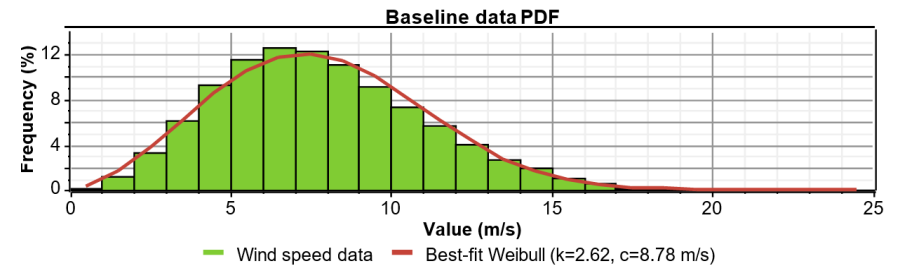

Figure 5. Fair Isle wind speed PDF

The Fair Isle wind resource has the following key characteristics to be considered for wind energy resource assessment:

Annual average wind speed: $7.8 \mathrm{~m} / \mathrm{s}$

Weibull: $\mathrm{k}=2.62, \mathrm{c}=8.78 \mathrm{~m} / \mathrm{s}$

Hour of peak wind speed: 13:00

3) Wind turbines: Figures 6 and 7 illustrate the power curve for the $100 \mathrm{~kW}$ and $60 \mathrm{~kW}$ turbines based on Cummings data. WTG 2 is significantly limited at wind speeds exceeding $15 \mathrm{~m} / \mathrm{s}$ and cuts out at $25 \mathrm{~m} / \mathrm{s}$, whereas WTG1 continues to operate at higher wind speeds.

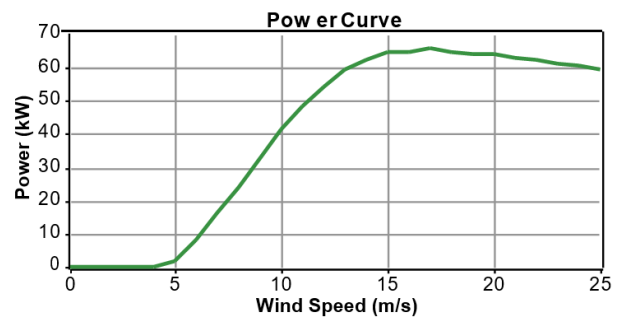

Figure 6. $60 \mathrm{~kW}$ wind turbine power curve

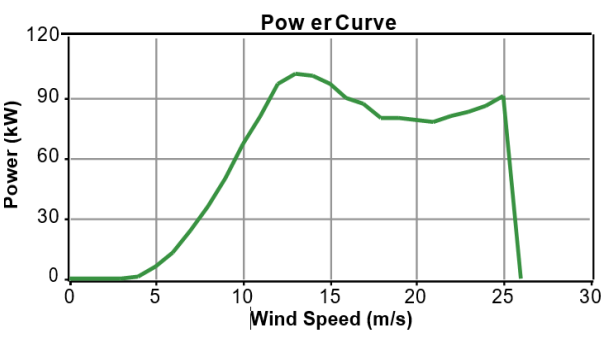

Figure 7. $100 \mathrm{~kW}$ wind turbine power curve

4)Diesel Generator: Figure 8 shows the diesel generator efficiency curve. It can be seen that below 30\% rating, the diesel generator efficiency is very low.

5)Dump load:The archive data for Fair Isle states on average $182 \mathrm{MWh}$ of wind energy is dumped annually; the variation of this dump load expressed monthly is illustrated in Figure 9.

It can be inferred that most of the wind energy is dumped during the winter months when wind speeds are at their highest. 


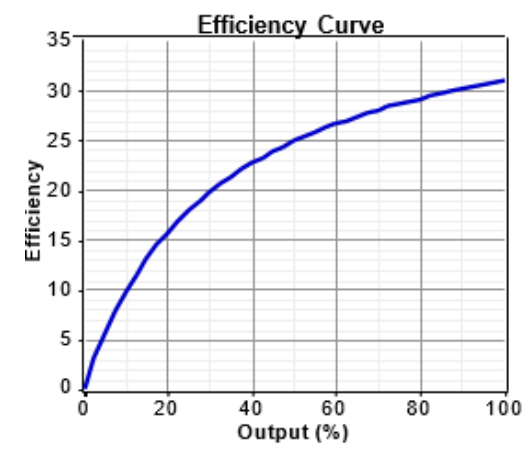

Figure 8. Diesel generator efficiency curve

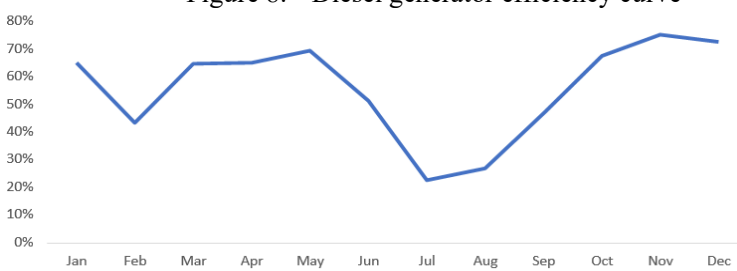

Figure 9. Fair Isle average monthly dumped wind energy as a percentage of that available

\section{B. Base model simulation}

Figure 10 illustrates the HOMER layout for the base model verification with an aggregated dump load for both wind turbines and all other loads represented as a primary load.

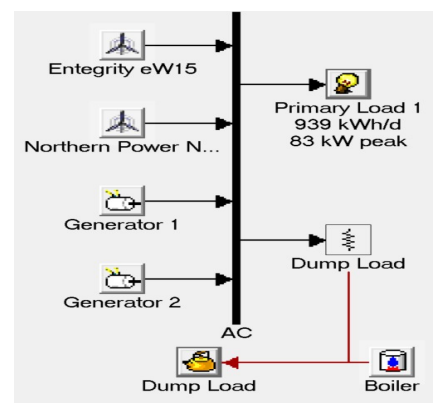

Figure 10. Base model configuration in HOMER

Table III summarizes the simulation results. It can be seen that approximately $60 \%$ of the monthly wind energy is dumped which is a close approximation to the actual system performance illustrated in Figure 9.

TABLE III. HOMER BASE MODEL SIMULATION RESULTS

\begin{tabular}{|l|c|c|}
\hline \multicolumn{3}{|c|}{ Energy Production (kWh/yr) } \\
\hline Wind turbines & 795,463 & $93 \%$ \\
\hline Diesel generators & 55,621 & $6 \%$ \\
\hline Total & 851,084 & $100 \%$ \\
\hline \multicolumn{2}{|c|}{ Energy Utilization (kWh/yr) } \\
\hline Primary AC load & 342,502 & $40 \%$ \\
\hline Excess electricity & 508,582 & $60 \%$ \\
\hline Total & 851,084 & $100 \%$ \\
\hline Diesel consumption (1/yr) & 21,178 \\
\hline
\end{tabular}

\section{Average hourly wind power profile}

Figure 11 and Table IV present the seasonal and hourly average wind power profiles derived from simulation. Two key characteristics can be elicited from these results:

a) On average the total available hourly wind power exceeds the demand by $58 \mathrm{~kW}$. Taking the average hourly demand to be $97 \mathrm{~kW}$ from Table III, this equates to an average annual penetration of $163 \%$, where $100 \%$ penetration is recorded when the wind generation matches the load.

b) Average hourly wind power penetration is highest during the hours 23:00 - 07:00 when the load demand is lowest irrespective of seasonal variation in total hourly system demand. It can therefore be concluded that during these hours the impacts of wind stochasticity would be most noticeable requiring curtailment and dump load action to maintain grid frequency and voltages within statutary limits.

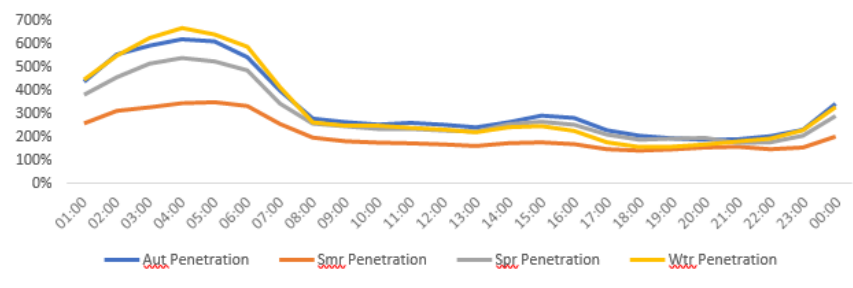

Figure 11 . Seasonal hourly average wind penetration potential

TABLE IV. Seasonal Average Excess Wind Power

\begin{tabular}{|c|c|}
\hline Season & $\begin{array}{c}\text { Average hourly excess } \\
\text { wind power (kW) }\end{array}$ \\
\hline Winter & 75 \\
\hline Spring & 59 \\
\hline Summer & 30 \\
\hline Autumn & 69 \\
\hline Seasonal Average & 58 \\
\hline
\end{tabular}

Although on average, there is sufficient wind generation, seasonal and hourly variation in both wind resource and demand means that generation exceeds load during the night hours. Excess power is currently dumped into water heating, however EV charging can be used as an alternative control mechanism.

\section{EV Charging}

The EV charging impact analysis is based on the assumption of using one Nissan Leaf PEV per house which has a battery capacity of $24 \mathrm{kWh}$ and individual vehicle charging load of $3 \mathrm{~kW}$ from standard single phase $13 \mathrm{~A} 230 \mathrm{~V}$ outlets. To simulate EV charging, a deferable DC load with inverter sized to represent lumped multiples of $3 \mathrm{~kW}$ was added to the AC primary load in HOMER, which would be supplied mainly when excess wind energy is available.

\section{1) Unscheduled EV Charging:}

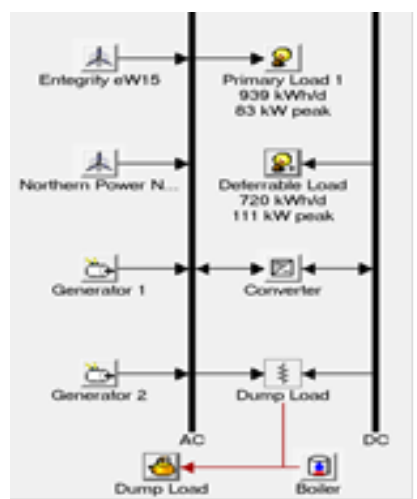

Figure 12. HOMER model configuration to simulate unscheduled EV charging

From the daily average charging load profile for $30 \mathrm{EVs}$ in Figure 13, it can be seen that the amount of excess power 
required to charge vehicles throughout the day varies significantly.

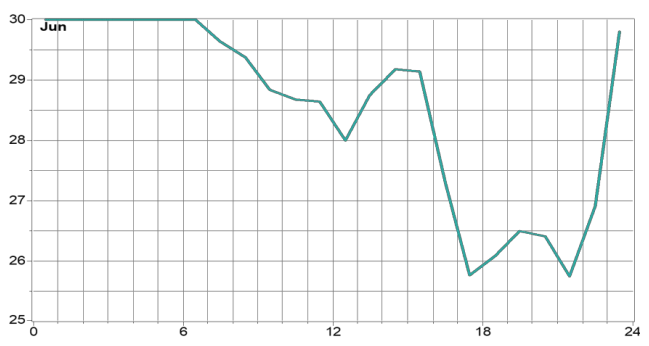

Figure 13. excess wind power $(\mathrm{kW})$ available for EV charging varying with time of day (h)

Additionally, due to population's activities during the hours of 07:00 - 21:30, the available excess wind power for EV charging varies sharply inter-hourly as shown in Figure 13. Hence, the number of EVs charging cannot be set and could result in increased diesel usage. Nevertheless, the highest charging availability coincides with the periods of low domestic loads between the hours of 22:00 - 07:00.

2) Scheduled EV charging: The simulation load profile and coincident wind power profile show that the daily periods of highest wind power penetration occurring between the hours of 22:00 - 07:00 when domestic load demand is lowest. Hence scheduled charging was selected to occur during the hours 22:00 -07:00 each day. Figure 15 shows the resulting scheduled EV charging load profile for $30 \mathrm{EVs}$.

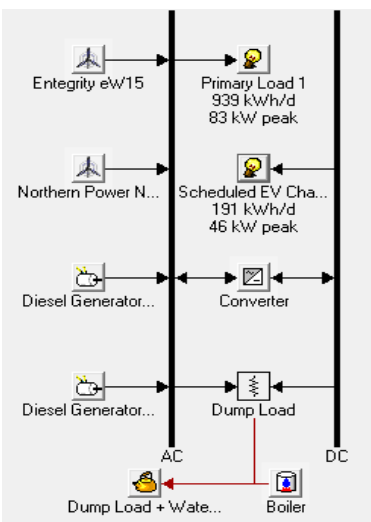

Figure 14. Scheduled charging configuration

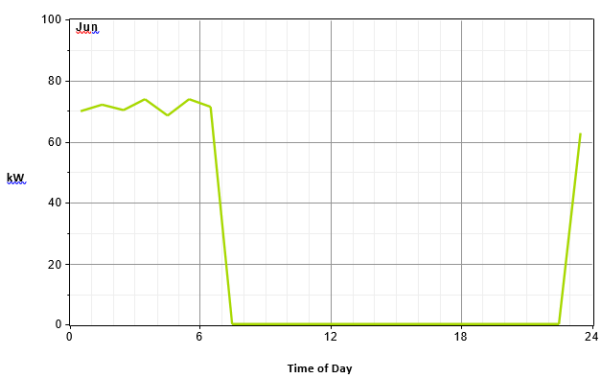

Figure 15. Scheduled EV charging profile

\section{E. Determination of optimal number of EVS}

When the load profile is compared with the wind generation, both with and without charging demand, it can be seen that seasonal variation plays a significant role wherein the optimal number of EVs is constrained by the summer seasonal average wind power. The optimal number is that required to minimise the need for diesel usage for $\mathrm{EV}$ charging loads during the summer period. From Figure 16, it can be seen that $8 \mathrm{EVs}$ are the optimal number beyond which the scheduled charging load will exceed the available average wind power. This assumes that each EV will fully charge and absorb $24 \mathrm{kWh}$ each night.

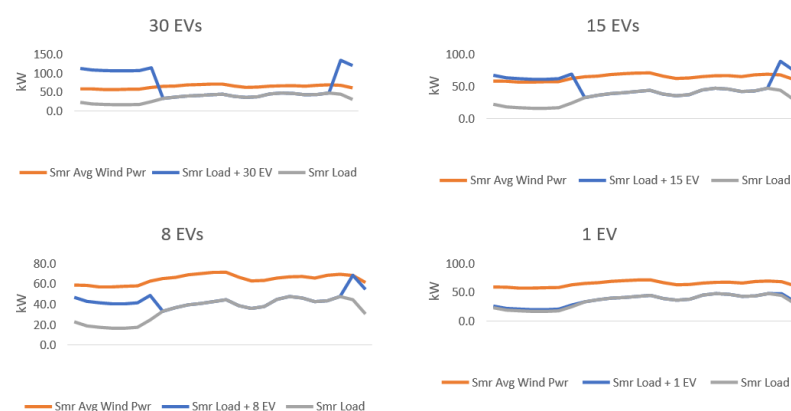

Figure 16. Summer wind power and load profiles with scheduled EV charging

Additionally, the impact of scheduled charging during the hours of 22:00 - 07:00 has resulted in a more level net load at any time of year. This can be seen by comparing Figure11 with Figure 17

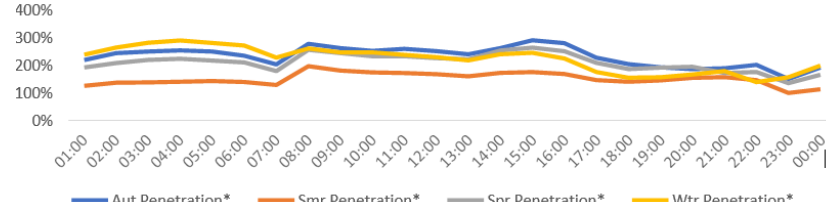

Figure 17. Average hourly wind power penetration with scheduled charging of $8 \mathrm{EVs}$

\section{F. Power Flow Analysis using IPSA simulation}

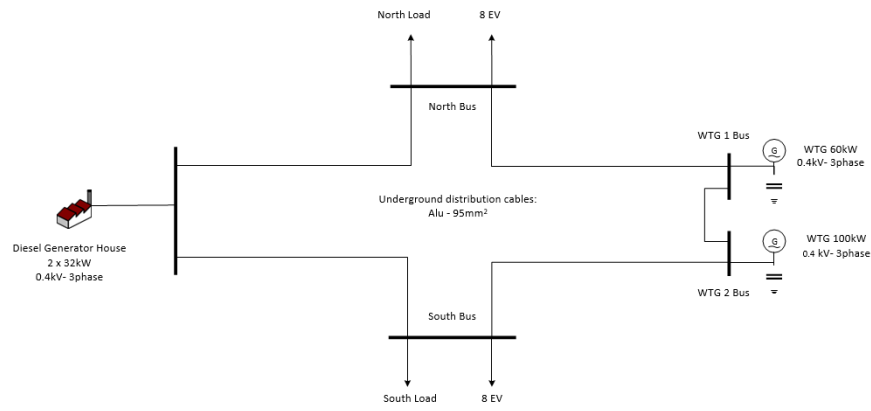

Figure 18. Fair Isle power system model for IPSA

The power system illustrated in Figure 18 was built in IPSA and the following results were obtained:

TABLE V. POWER FLOW BEFORE SCHEDULED 8 EV CHARGING

\begin{tabular}{|l|c|c|c|c|c|c|c|}
\hline $\begin{array}{c}\text { Bus } \\
\text { Name }\end{array}$ & $\begin{array}{c}\text { Voltage } \\
\text { Magnitude } \\
\text { (pu) }\end{array}$ & $\begin{array}{c}\text { Voltage } \\
\text { Angle } \\
\text { (deg) }\end{array}$ & $\begin{array}{c}\text { Total Real } \\
\text { Generation } \\
\text { (kW) }\end{array}$ & $\begin{array}{c}\text { Total } \\
\text { Reactive } \\
\text { Generation } \\
\text { (kVAr) }\end{array}$ & $\begin{array}{c}\text { Total } \\
\text { Real } \\
\text { Load } \\
(\mathbf{k W})\end{array}$ & $\begin{array}{l}\text { Total } \\
\text { Reactive } \\
\text { Load } \\
(\mathbf{k V A r})\end{array}$ & $\begin{array}{c}\text { Load } \\
\text { power } \\
\text { factor }\end{array}$ \\
\hline DG & 1 & 0 & -103.175 & -8.84264 & 0 & 0 & 0 \\
\hline WTG 1 & 1.00035 & 0.00408626 & 47 & 0 & 0 & 0 & 0 \\
\hline North & 1.00016 & 0.00206258 & 0 & 0 & 9 & 2.95816 & 0.95 \\
\hline South & 1.00018 & $2.10 \mathrm{E}-03$ & 0 & 0 & 9 & 2.95816 & 0.95 \\
\hline WTG 2 & 1.00039 & 0.00415271 & 74 & 0 & 0 & 0 & 0 \\
\hline
\end{tabular}


In Table $\mathrm{V}$ the impact of the scheduled charging of $8 \mathrm{EVs}$ is observable as a $23 \%$ reduction in excess power flowing to the diesel generator slack bus. As the wind resource is lowest during the summer months the power flow results show the scheduled charging load is just sufficient to be met by the wind power with an average of $8 \mathrm{~kW}$ excess flowing to the slack bus. If the number of EVs exceeds 8 , diesel generation would be required to meet the charging demand with the generators operating a low loads and low efficiencies. Alternatively, the charging rate could be managed so that this did not occur.

TABLE VI. WINTER POWER Flow With SCHEDULED 8 EV CHARGING

\begin{tabular}{|l|c|c|c|c|c|c|c|}
\hline $\begin{array}{c}\text { Bus } \\
\text { Name }\end{array}$ & $\begin{array}{c}\text { Voltage } \\
\text { Magnitude } \\
\mathbf{( p u )}\end{array}$ & $\begin{array}{c}\text { Voltage } \\
\text { Angle } \\
\mathbf{( d e g})\end{array}$ & $\begin{array}{c}\text { Total Real } \\
\text { Generation } \\
(\mathbf{k W})\end{array}$ & $\begin{array}{c}\text { Total } \\
\text { Reactive } \\
\text { Generation } \\
\mathbf{( k V A r}\end{array}$ & $\begin{array}{c}\text { Total } \\
\text { Real } \\
\text { Load } \\
(\mathbf{k W})\end{array}$ & $\begin{array}{l}\text { Total } \\
\text { Reactive } \\
\text { Load } \\
(\mathbf{k V A r})\end{array}$ & $\begin{array}{l}\text { Load } \\
\text { power } \\
\text { factor }\end{array}$ \\
\hline DG & 1 & 0 & -79.0591 & -2.55391 & 0 & 0 & 0 \\
\hline WTG 1 & 1.00031 & 0.00444648 & 47 & 0 & 0 & 0 & 0 \\
\hline North & 1.00012 & 0.00190658 & 0 & 0 & 21 & 2.95816 & 0.990224 \\
\hline South & 1.00014 & $2.05 \mathrm{E}-03$ & 0 & 0 & 21 & 2.95816 & 0.990224 \\
\hline WTG 2 & 1.00034 & 0.00474177 & 74 & 0 & 0 & 0 & 0 \\
\hline
\end{tabular}

TABLE VII. Summer POWER Flow With SCHEduled 8 EV CHARging

\begin{tabular}{|l|c|c|c|c|c|c|c|}
\hline $\begin{array}{c}\text { Bus } \\
\text { Name }\end{array}$ & $\begin{array}{c}\text { Voltage } \\
\text { Magnitude } \\
\text { (pu) }\end{array}$ & $\begin{array}{c}\text { Voltage Angle } \\
\text { (deg) }\end{array}$ & $\begin{array}{c}\text { Total Real } \\
\text { Generation } \\
\text { (kW) }\end{array}$ & $\begin{array}{c}\text { Total } \\
\text { Reactive } \\
\text { Generation } \\
\text { (kVAr) }\end{array}$ & $\begin{array}{c}\text { Total } \\
\text { Real } \\
\text { Load } \\
(\mathbf{k W})\end{array}$ & $\begin{array}{c}\text { Total } \\
\text { Reactive } \\
\text { Load } \\
(\mathbf{k V A r})\end{array}$ & $\begin{array}{c}\text { Load } \\
\text { power } \\
\text { factor }\end{array}$ \\
\hline DG & 1 & 0 & -8.85538 & -3.22505 & 0 & 0 & 0 \\
\hline WTG 1 & 1.00009 & 0.000508582 & 16 & 0 & 0 & 0 & 0 \\
\hline North & 1.00001 & $-6.48 \mathrm{E}-05$ & 0 & 0 & 20.1 & 2.66234 & 0.991342 \\
\hline South & 1.00002 & $-3.06 \mathrm{E}-05$ & 0 & 0 & 20.1 & 2.66234 & 0.991342 \\
\hline WTG 2 & 1.00011 & 0.000576888 & 33 & 0 & 0 & 0 & 0 \\
\hline
\end{tabular}

Notably in all simulation cases, the bus voltages do not fall outside the statutory limits for UK power networks. Since the scheduled EV charging is set for periods of low system demand, the network impact is within design limits under normal operating conditions.

From the simulation results the following key findings have been derived:

- $\quad$ PEV charging can provide a suitable low-cost balancing mechanism to wind power instability by enabling demand side management functionality.

- On island grids, scheduled EV charging during periods of low system demand is better applied than unscheduled charging as wind penetration has been shown to be greatest during the minimum system load demand hours and would therefore have the greatest stability impact at this point.

- Although PEV charging can provide added benefits for wind power stability on island nations, consideration has to be given to the minimum resource availability in determining the optimal number of EVs to add to the existing system load. Exceeding this amount will undermine the fuel savings achievable.

\section{CONCLUSIONS}

Due to the stochastic nature of wind, large scale penetration into island hybrid power systems can result in voltage and frequency excursions beyond normal operable limits. The literature reviews, case study and simulations using data for Fair Isle have shown that this can be avoided using scheduled EV charging during periods of low system demand when power system instability is most likely to occur.

Ongoing research into V2G control, coordination technologies for grid regulation functionality and utilisation of variable speed converter type WTGs promise improved grid stability and present an optimistic future in which island grids can be largely powered by wind generators without diesel generator back up.

\section{REFERENCES}

[1] K. Shivarama Krishna and K. Sathish Kumar, "A review on hybrid renewable energy systems", Renewable and Sustainable Energy Reviews, vol. 52, pp. 907-916, 2015.

[2] Y. Kuang, Y. Zhang, B. Zhou, L. Li, C. Li, Y.Cao and L. Zeng "A review of renewable energy utilization in islands", Renewable and Sustainable Energy Reviews, vol. 59, pp. 504-513, 2016

[3] T. Ikegami, C. T. Urabe, T. Saitou and K. Ogimoto, "Numerical definitions of wind power output fluctuations for power system operations", Renewable Energy, vol. 115, pp. 6-15, 2018.

[4] G. Ren, J. Liu, J. Wan, Y. Guo and Y. Daren, (2017) "Overview of wind power intermittency: Impacts, measurements, and mitigation solutions", Applied Energy, vol. 204, pp. 47-65, 2017.

[5] X. Luo, S. Xia and K. W. Chan, "A decentralized charging control strategy for plug-in electric vehicles to mitigate wind farm intermittency and enhance frequency regulation", Journal of Power Sources, vol. 248, pp. 604-614, 2014

[6] A. B. Gallo, J. R. Simões-Moreira, H. K. M. Costa, M. M. Santos and E. Moutinho dos Santos, "Energy storage in the energy transition context: A technology review", Renewable and Sustainable Energy Reviews, vol. 65 , pp. 800-822.

[7] Fair Isle Development Authority, "Turbine," Fair Isle, https://web.archive.org/web/20070915103001/http://www.fairisle.org.u $\mathrm{k}: 80 / \mathrm{FIECo} /$ renewed/turbines.html

[8] Fair Isle Development Authority, "Speed Control," Fair Isle, https://web.archive.org/web/20081118202150/http://www.fairisle.org.u $\mathrm{k} / \mathrm{FIECo} / \mathrm{renewed} /$ speed control.html.

[9] Fair Isle Development Authority, "New Supply," Fair Isle, https://web.archive.org/web/20070916121112/http://www.fairisle.org.u $\mathrm{k}: 80 / \mathrm{FIECo} /$ renewed/new sup ply.html.

[10] Wind \& Sun complete UK's largest off-grid battery inverter system and help bring 24 hour electricity to Fair Isle, Britain's most remote community http://www.windandsun.co.uk/news 